\title{
VOLUNTARY ACCELERATION OF THE HEART BEAT *
}

\author{
HOWARD F. WEST, M.D., AND WILLIAM E. SAVAGE, A.B. \\ BOSTON
}

Favill and White ${ }^{1}$ have recently studied a person having the ability to increase the rate of the heart at will. This was the fourteenth of such persons to be reported (see Footnote 2). Electrocardiograms have been made of three of these persons, but only in the studies of Favill and White were the effects of atropin on the ability to accelerate observed. These authors, with others who have studied similar instances, were led to believe that the action of the accelerator nerves was the chief factor in the mechanism of this type of acceleration.

The following observations are reported in order to add another case to the series and because certain differences in results were obtained from those previously recorded.

The subject is a young medical student who is entirely healthy and is apparently free from all physical and neurotic defects. He has had no cardiovascular symptoms whatever and physical examination shows the heart to be of normal size and free from abnormal sounds and murmurs. Attacks of tachycardia have never been noticed. He discovered the ability to increase his heart rate voluntarily during the course in physiology in his freshman year and has practiced it only at times of making observations such as the following.

Electrocardiograms were made with an instrument of the Cambridge pattern so standardized that a deflection of $10 \mathrm{~mm}$. was produced by a current of $1 \mathrm{~m}$. volt. Continuous rolls of bromid paper were used so that the records covered fairly long periods of time. Radial pulse tracings were made with a Mackenzie polygraph, and blood pressure readings were made before and during periods of acceleration. The effects of large doses of atropin were tested.

During the period of acceleration there is a very slight increase in

\footnotetext{
* Received for publication May 27, 1918.

* From the Medical Clinic of the Peter Bent Brigham Hospital and the Harvard Medical School.

1. Favill, J., and White, P. D.: Heart, 1917, 6, 175.

2. Koehler, M.: Arch. f. d. ges. Physiol., 1914, 158, 579. Pease, E. A.: Boston Med. and Surg. Jour., 1889, 120, 525. Tarchanoff, J. R.: Arch. f. d. ges. Physiol., 1885, 35, 109. Tuke, D. H.: Illustrations of the Influence of the Mind on the Body in Health and Disease, Designed to Elucidate the Action of the Imagination, London, 1872. Van de Velde, Th. H.: Arch. f. d. ges Physiol., $1897,66,232$.
} 
the rate and the depth of respiration (Fig. 3), and the pupils dilate moderately as recorded by other observers. No definite physical effort is made, but constant mental concentration must be maintained, which, after several closely repeated trials, becomes quite fatiguing.

Figure 1 shows a radial tracing and illustrates a typical period of acceleration of short duration. The rate begins to increase almost immediately following the word of command and reaches its maximum after about ten heart cycles. All our tracings show a decrease in amplitude of the pulse waves rather than an increase with marked dicrotism, as shown by Favill and White. ${ }^{1}$

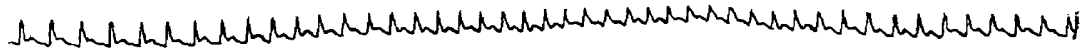 1}

Fig. 1.-Radial tracing showing typical period of acceleration of short duration. Command to accelerate indicated by arrow.

There was a distinct rise in blood pressure with each acceleration with the exception of the effort at the height of the atropin effect, when there was a drop of $10 \mathrm{~mm}$. from the reading made five minutes before. The latter reading, however, was $10 \mathrm{~mm}$. higher than the first record made before the atropin was given. The greatest increase noted was one of $18 \mathrm{~mm}$. accompanying an acceleration of 27 beats per minute. (See accompanying table.)

Table Giving Data of Author's Case

\begin{tabular}{|c|c|c|c|c|c|}
\hline \multirow{2}{*}{ Time, P. M. } & \multirow{2}{*}{ Pulse Rate } & \multirow{2}{*}{ Increase } & \multicolumn{2}{|c|}{ Blood Pressure } & \multirow{2}{*}{ Remarks } \\
\hline & & & Systolie & Diastolie & \\
\hline $4: 20$ & 69 & .. & 120 & 70 & \\
\hline $4: 22$ & 96 & 27 & 138 & 75 & Volun tary acceleration \\
\hline $4: 25$ & 66 & .. & 120 & 70 & \\
\hline $4: 27$ & .. & .. & $\cdots$ & .. & Atropin $0.002 \mathrm{gm}$. subcu- \\
\hline $4: 30$ & 60 & & & & \\
\hline $4: 55$ & 66 & .. & 120 & 70 & $\begin{array}{l}\text { Beginning dryness of } \\
\text { mouth }\end{array}$ \\
\hline $5: 10$ & 74 & .. & 115 & 70 & Pupils slightly dilated; \\
\hline $5: 15$ & 86 & 12 & 130 & 75 & Voluntary acceleration \\
\hline $5: 20$ & 94 & .. & 130 & 70 & Dizzy, slightly nauseated \\
\hline $5: 25$ & 102 & 8 & 120 & 70 & Voluntary acceleration \\
\hline $5: 35$ & .. & .. & ... & .. & Cardiogram taken. \\
\hline $5: 45$ & 76 & .. & 134 & 80 & $\begin{array}{c}\text { Dryness } \\
\text { marked }\end{array}$ \\
\hline
\end{tabular}


Electrocardiograms of this student show no distinctive characteristics other than a slight notching of $R$ and a diphasic $T$ in the third lead. There is a definite, but not unusually marked, sinus arrhythmia (Fig. 2). During the periods of acceleration (Fig. 3) there was no change in the P-wave, in the P-R interval, nor in the distance from the beginning of $R$ to the end of $T$. The amplitude of $T$ was not changed. There was some thythmic variation in the height of $\mathrm{R}$ both

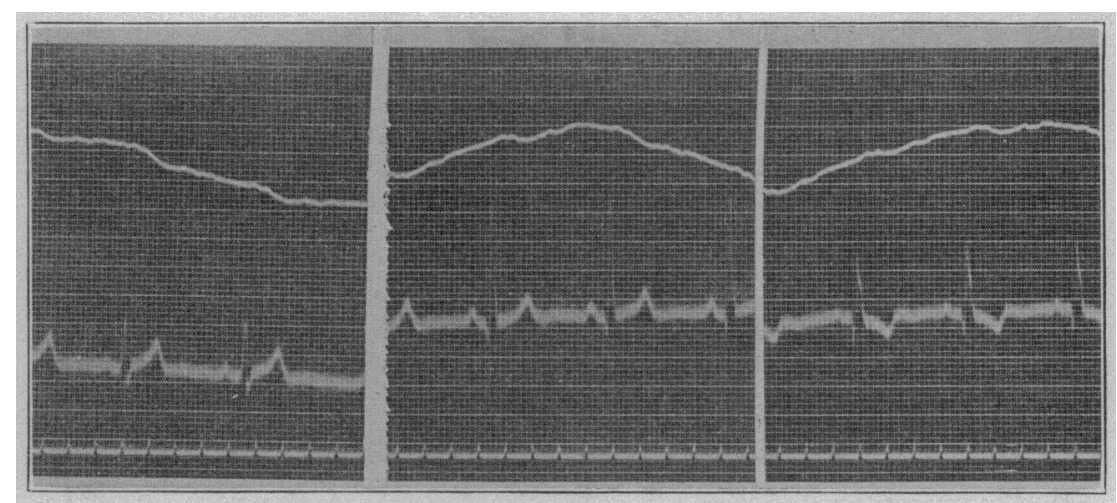

Fig. 2.--Leads I, II and III of subject at rest. Time in $1 / 5$ and $1 / 25$ second.

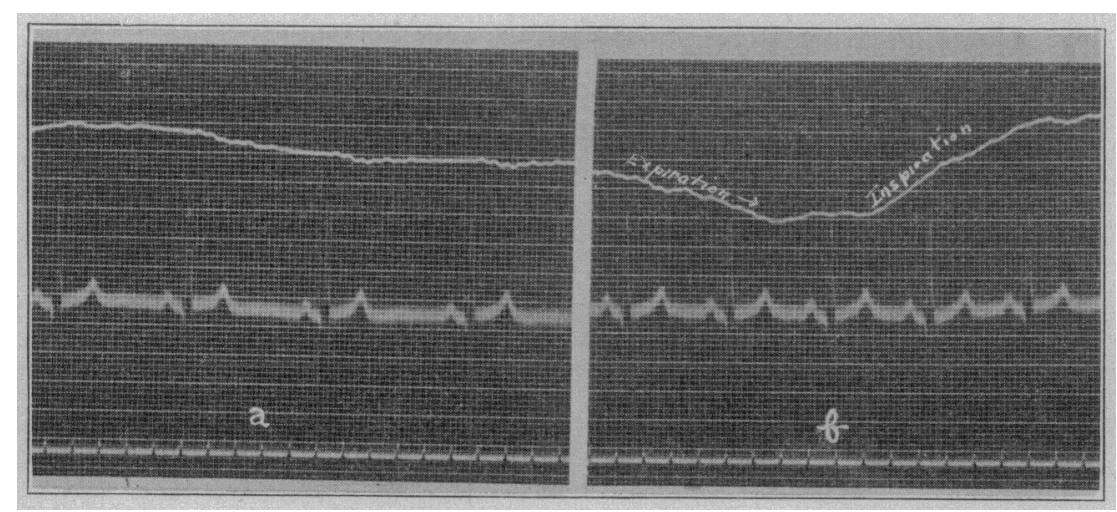

Fig. 3.-Lead II; $a$, just before command to accelerate; $b$, at height of acceleration. Line above electrocardiogram records respiratory movements obtained by pneumograph and tambour.

before and during the period of acceleration. The general average of the $\mathrm{R}$ deflections was slightly lower during the periods of acceleration, but by not more than one-tenth of the height preceding the increased rate.

After subcutaneous injection of $0.002 \mathrm{gm}$. of atropin sulphate the rate was increased from 69 to 94 beats per minute. Electrocardiograms taken at this time show a very slight increase in the amplitude 
of $\mathrm{T}$ in the first lead and a correspondingly slight decrease in the height of $R$. No change in the distance from the beginning of $R$ to the end of $T$ could be made out. The sinus arrhythmia was almost, but not completely, obliterated. If one calculates minute rate on the shortest and longest cycles shown by the electrocardiogram at this time, a difference of 8 beats per minute results, which corresponds to the acceleration noted at the wrist as shown in the table. The ten beats preceding voluntary acceleration at the height of the atropin effect occurred at the rate of 80 per minute, the ten beats at the height of voluntary acceleration at 87 per minute, an increase of seven beats.

When respirations were forced without atropin the sinus arrhythmia becomes more marked as shown in Figure 5. If the rate were calculated on the basis of that seen at the beginning of inspiration,

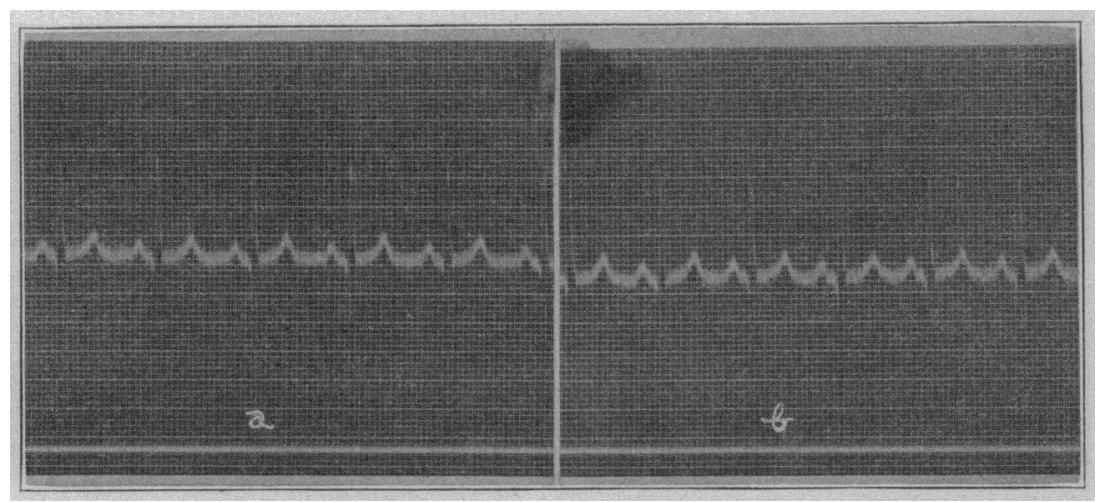

Fig. 4.-Lead II, sixty-eight minutes following injection of atropin. $a$, just before command to accelerate; $b$, at height of acceleration.

where it is most rapid, it would approximate 79 per minute. If calculated on the expiratory rate it would give approximately 54 beats per minute, or a difference of 25 beats. The greatest voluntary acceleration recorded in our observations was one of 27 beats per minute, which it would seem could be easily accounted for by vagus activity, assuming that sinus arrhythmia of the respiratory type is due to rhythmic changes in vagus inhibition. Pressure on the right vagus produced a prompt slowing of the heart rate from 72 to 48 beats per minute.

\section{DISCUSSION}

The identification of the mechanism involved in these cases is somewhat difficult and perhaps cannot be definitely attributed to either vagus or accelerator action alone, for there are probably no stages in the heart's activities in which both are not active to a greater or less extent. It would seem, however, that in this person our observations 
point more to vagus than to accelerator domination during periods of acceleration. We have not been able to observe the marked decrease in the amplitude of $\mathrm{R}$ nor the increase in $\mathrm{P}$ and $\mathrm{T}$ during the increased rate as recorded by Favill and White and mentioned by Lewis and Cotton ${ }^{3}$-quoting Rothberger and Winterberg-as characteristic of effects of stimulation of the stellate ganglia. Nor have we obtained any decrease in the length of systole which was so marked in the experiments of $\mathrm{Hunt}^{4}$ following direct stimulation of the accelerator nerves, and by Patterson ${ }^{5}$ following intravenous injection of epinephrin.

Animal experiments have also shown that following stimulation of the accelerator nerves there is a prolonged latent period, from five to ten seconds, while the acceleration in these persons showing volun-

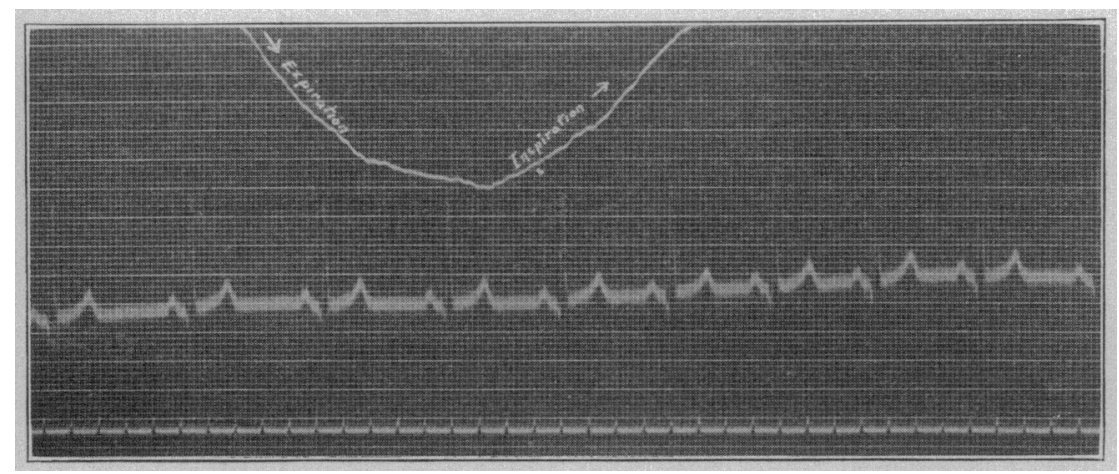

Fig. 5.-Electrocardiogram taken during period of forced respiration.

tary control begins almost immediately, reaching a maximum, it is true, after a few seconds of effort.

Then again, the degree of acceleration during our observations seemed to be definitely within the extremes of rate shown in a study of the normal sinus arrhythmia. The results following injection of atropin were quite at variance with those reported by Favill and White, who found no reduction in the ability to accelerate. As has already been pointed out, there was a definite and corresponding decrease in the sinus arrhythmia and the ability to accelerate at the height of the atropin effect in our observations. Had the atropin been given in sufficiently large dose completely to paralyze the vagus terminals we believe the ability voluntarily to change the rate would have been abolished or nearly so.

3. Lewis, Thos., and Cotton, T. F.: Proc. Physiol. Soc., June 28, 1913.

4. Hunt, R.: Am. Jour. Physiol., 1899, 11, 395.

5. Patterson, S. W.: Proc. Royal Soc., 1915, 88, 371. 
Gasser and Meek, ${ }^{6}$ after studying the mechanism of acceleration accompanying exercise, were led to conclude that the primary increase was due to a decrease in vagus inhibition, but that this was probably augmented "in times of great need" by accelerator influences. Our observations are entirely in accord with this view. It may be that those persons showing higher degrees of voluntary increase in rate may be able to add accelerator stimuli to a primary vagus release.

6. Gasser, H. S., and Meek, W. J.: Am. Jour. Physiol., 1914, 34, 48. 